\title{
Rural Telephony: A Socio-Economic Case Study
}

\author{
Sayandeep Sen \\ Dept. of Computer Science and Engg. \\ Indian Institute of Technology \\ Kanpur, India 208016 \\ Email: sdsen AT iitk.ac.in
}

\author{
Sukant Kole \\ Media Lab Asia \\ Indian Institute of Technology \\ Kanpur, India 208016 \\ Email: skole AT iitk.ac.in
}

\author{
Bhaskaran Raman \\ Dept. of Computer Science and Engg. \\ Indian Institute of Technology \\ Kanpur, India 208016 \\ Email: braman AT iitk.ac.in
}

\begin{abstract}
Information and Communication Technology (ICT) has the potential to bring in development to rural areas in the third world. Any deployment of technology however should be backed by a positive economic activity to be sustainable. This paper reports on experience with the economics, as well as the social aspects of Voice-over-IP (VoIP) as a service. In Jan 2003, we established a WiFi link from a site with wired Internet connection to a remote village site. On learning the demand for a telephone facility at the village, we setup a VoIP service. The setup has been running with reasonable success since then. We have collected a wide variety of statistics on the usage of the service.

Although we used the relatively low-cost WiFi technology, the expenses have been high. The capital expense is dominated by antenna tower $(40 \mathrm{~m}$ : U.S.\$6,600). The WiFi equipment and the solar power system added significantly to the cost too (about U.S. $\$ 3,100)$. The revenue generated from the phone calls has averaged at about $\$ \mathbf{5 2} / \mathbf{m o n t h}$. Hence this service alone may not be sufficient, and other targeted services are necessary to sustain ICT in rural villages. However, on the positive side we think that telephony facility can attract potential ICT users to the setup since people can relate to the service immediately (unlike say, web browsing).
\end{abstract}

\section{INTRODUCTION}

Information and Communication Technology (ICT) has the potential to bring in socio-economic development to rural areas in the third world. A main requirement for providing the same to rural areas is the presence of Internet connectivity. While wired Internet connectivity is already present in urban areas of the developing regions, extending the same to rural areas has been a topic of significant research in recent times because of the additional constraints (cost-effectiveness, power efficiency) involved. IEEE 802.11 has been suggested as a possible lowcost alternative for providing last hop Internet connectivity to villages [1], [2].

Any deployment of technology should be backed by a positive economic activity to be sustainable in the long run. In this paper we document our experiences with setting up of a Voice-over-IP service based on a long distance WiFi link.

With the validation of the feasibility of long distance (order of tens of kilometers) $802.11 \mathrm{~b}$ based links, we had established the proof of concept that WiFi can perform well for outdoors [1]. Hence, we started working on development of some economic models for rural areas based on the applications of this technology.

During the course of interaction with the villagers at various sites we realized that they were not interested in Internet surf- ing. Villagers were more interested in voice communication using telephone.

To prove the feasibility of long distance VoIP based rural telephony, we selected the remote village of Sarauhan, henceforth called the Village Site (VS). The village lacks basic necessities like motorable road and reliable electricity, and is situated at a distance of 18 kilometers off the nearest highway. At this particular village, there was a high demand for telephony since the nearest telephone for the villagers was $6 \mathrm{~km}$ away. Our goal was to connect the village to a Landline Site $(L S)$, a site with wired Internet connectivity (following the terminology in [1]). We used our institute, Indian Institute of Technology at Kanpur as the Landline Site. The VS is 54 kilometers from our chosen $L S$ by road. We formed a direct link between $L S$ and $V S$, spanning an air-distance of $37 \mathrm{kms}$ in a single hop.

After installing VoIP equipments at the $L S$ and $V S$, we ran a one day telephony service on 04 Jan 2003 and found that the villagers were receptive to the idea of setting up of a public owned telephone service in the village itself. This prompted us to deploy an experimental VoIP based telephony setup at the village by utilizing the established wireless link. In this setup, there is an operator at the $V S$, who assists the users in making calls, collects revenue and does some necessary maintenance work, as well as informs us at the $L S$ about any malfunctioning in the setup. This setup at the village is called a Public Calling Office (PCO).

Under various practical considerations, the VoIP setup has undergone three phases in the deployment. The setup has been running with reasonable success for more than a year now. We have collected a wide variety of statistics on the usage of the service. We present a range of these statistics in this paper.

Although we have used the relatively low-cost WiFi technology, the expenses have been high. The capital expense is dominated by antenna tower: about U.S.\$6,600 for the $40 \mathrm{~m}$ tower. The WiFi equipment and the solar power system have been expensive as well: about U.S.\$3,100. The revenue generated from the phone calls alone have not been very high in comparison: about $\$ 52$ per month. This may not be sufficient, and we feel that other targeted services are necessary to sustain ICT in such settings.

We suggest various cost optimizations as well as an alternate revenue sharing model under which the VoIP service may be more financially viable. Also, the telephony facility can have a 
very important positive role to play. We think that a telephony facility can attract potential ICT users to the setup since people can relate to the service immediately. This is in contrast to urban locations where other services such as web browsing are more popular.

The rest of the paper is organized as follows. In Section II we describe the initial technical and administrative challenges that we had to face during deployment of infrastructure and how we solved them. We also mention the engineering changes done to fine-tune the setup. Section III documents our experiences (technical, business, and social) in operating this link for a period of over a year. In Section IV we analyze the given setup for financial viability based on the cost of initial infrastructure deployed, the monthly expenses incurred, and the revenue earned. We then propose a better (cost optimized) infrastructure for new deployments based on our experiences from the setup. We conclude in Section V.

\section{The Evolution of the VoiP Deployment}

The current VoIP deployment has evolved over three phases. We now describe this evolution.

The first phase of the VoIP deployment started with the oneday demo setup, on 04 Jan 2003, as mentioned in Section I. In this setup, we had a Foreign eXchange Station (FXS) device at the $V S$, and a Foreign eXchange Office (FXO) device at the $L S$. This is depicted in Figure 1. The FXO acted as the gateway between IP and the PSTN (Public Switched Telephone Network). The FXS at the VS enabled the use of a regular phone device, which people were already accustomed to (instead of using a VoIP phone device).

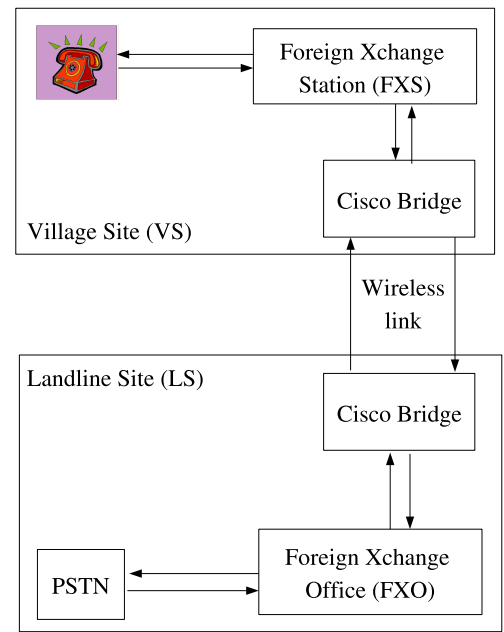

Fig. 1. Demo VoIP Setup

The wireless link uses a pair of Cisco a350 bridges, connected to high-gain directional antennae. We used parabolic grid antennae with $24 \mathrm{dBi}$ gain at either end, with the radios operating at a transmit power of $20 \mathrm{dBm}$. This is well within the regulatory emission limits [3]. At the $L S$ end, we used a tall building, $40 \mathrm{~m}$ high, and at the $V S$ end, we setup a $40 \mathrm{~m}$ tall antenna tower. This setup helps in achieving line-of-sight, which is required for WiFi links.

The demo VoIP setup was received quite enthusiastically by people in the village. Hence we decided to setup a VoIP-based PCO (Public Call Office) at the village. Two important issues had to be solved before we could take the step from a demo to a deployment:

Power Issue: Practically the VS received mains power offthe-grid for only 2-3 hours in a day. Even when power was available, it was well below the specified 220 Volts. Worse, it had a large variation as well: 90 to 120 V. Operating the VoIP setup under such unreliable power availability was difficult. In order to get by the problem, we planned the following:

1) Using a voltage stabilizer, for steadying the voltage supply.

2) Commissioning a solar power system with battery bank, to be used as the main power source.

3) Keeping a diesel-run power generator set as backup.

Billing Issue: The next important issue to address was that of billing. People are quite conscious about the bill, whenever they are charged for the calls. Although a billing system is built-in the VoIP boxes (FXO/FXS), they meter only the call from one VoIP box to other VoIP box. We however required that they meter the outgoing calls on the Public Switched Telephone Network (PSTN) line: based on the called destination.

Now, commercial PCOs already have the necessary billing machine to meter outgoing calls based on the destination (akin to public telephone booths in several cities/countries). To get around our billing problem, we decided to make use of the services of a commercial PCO. Under this setup, we termed the Village Site (VS) as a PCO extension counter (of the commercial PCO).

Whenever a caller at the VS wanted to make a call from the PCO extension counter, he/she would dial the number of the VoIP phone at the commercial PCO end. The operator at the commercial PCO will (manually) make a PSTN call on behalf of the caller. The operator will then give the line to the caller at the VS using a two-line phone. This is depicted in Fig 2.

At the end of call, the billing machine at the commercial PCO prints the bill and the operator at the PCO communicates the same to the operator at the extension counter. The latter then collects the cash from the caller at the VS. At the end of day, the two operators exchange the revenue collected and the bills.

For our setup, a commercial PCO at a distance (aerial) of approximately $6 \mathrm{~km}$ from our village site agreed to take part in this venture. We setup a WiFi link connecting the commercial PCO to the VS. The experimental PCO extension counter was inaugurated on 03 Jan 2004 for commercial operation.

\section{Fine-tuning the setup:}

After working with this setup for some time, we ran into non-technical problems with the commercial PCO operator. The commercial PCO operator did get additional revenue from the extension counter at the village site. However, he also 


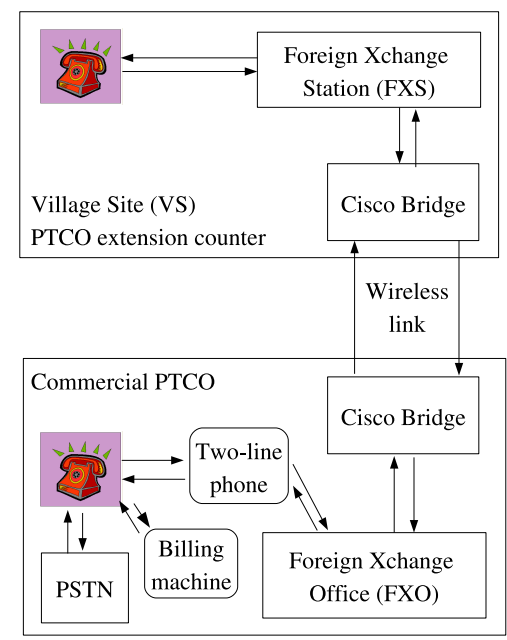

Fig. 2. First VoIP Setup

had expenses for powering up the networking equipments: the commercial PCO site also had erratic power supply hence he had to use alternative methods to generate his own power. The experimental arrangement with the commercial PCO had to be dismantled.

Our only reason for depending on the commercial PCO was for billing. In the next phase of the setup, we looked for offthe-shelf PCO billing machines. We deployed such a PCO billing machine at the $V S$ to take care of the billing problem. We then decided to revert to our demo setup, of having direct connectivity to the $V S$ from the $L S$. This is our current setup, and is shown in Fig 3.

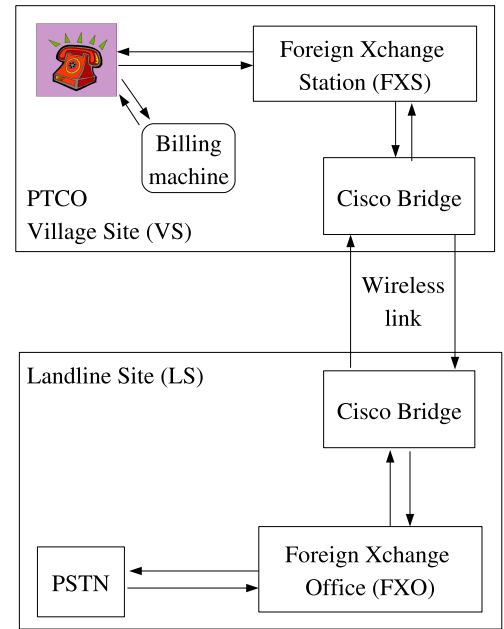

Fig. 3. Current VoIP Setup

Under the current setup, the FXO at the $L S$ is connected to a PBX (Private Branch eXchange). Whenever somebody wants to make a call from $V S$, he has to dial 0, wait for another dialtone, then dial the intended telephone/mobile number. The call thus first terminates at the FXO at the $L S$, then subsequently connects to the outside world. However, one can talk to any telephone number within the PBX of the $L S$, from the $V S$ at no extra PSTN billing cost.

As a further enhancement to the setup, we have integrated the hardware of the WiFi client with the VoIP FXS module. These modules are now in a single box, and can replace the bridge and FXS at the VS. This box is analogous in functionality to a cordless phone system. We just need to connect three things to this box at the VS to have a VoIP phone: (a) an appropriate external antenna (WiFi), (b) the billing machine, and (c) a standard analog telephone instrument. However, we have not yet installed this integrated hardware box at the $V S$.

\section{EXPERIENCES WITH THE DEPLOYMENT}

In this section we document the various experiences that we have gained from running the VoIP service for a period of over a year. In Section III-A we describe the facts about the operational performance of the setup i.e., its reliability, and characterize the main causes of service disruption. In Section III-B we present statistics on the business performance of the setup. We then present in Section III-C a few interesting points about the social characteristics related to the VoIP service usage at the $V S$.

For the various data presented below, we used one of two sources of information. One of the sources was a database maintained at $L S$ which had record of the duration and cost of each call made from the VS. This database was maintained as part of the PBX system at the $L S$. Apart from this database, the other source of information was the log maintained by the PCO operator at the VS. Depending on the information, this log was maintained on a per-day basis or on a per-call basis. The PCO operator either reported the information back to us at the $L S$ at the beginning of the next working day, or on a monthly basis.

\section{A. Operational performance}

During the initial few days of operation of the PCO, there were a few bad/erroneous calls, since the PCO operator (a resident of $V S$ ) was still getting used to the procedure. Once he achieved a suitable degree of expertise, there were no more such bad calls.

We collected information on the functioning of the PCO, from the period of August 2004 to September 2005 by monitoring the duration of time for which the service was up and available for usage. This information was maintained by the PCO operator and was passed on to us on a monthly basis. The operator maintained the service availability information at the granularity of one day. We found out that, on an average in a month approximately five days go without any PCO service due to some technical problems. Such problems fall into three categories:

1) Solar power system failure at $V S$.

2) Telephone network failure at $L S$.

3) Router configuration problem at $L S$. 


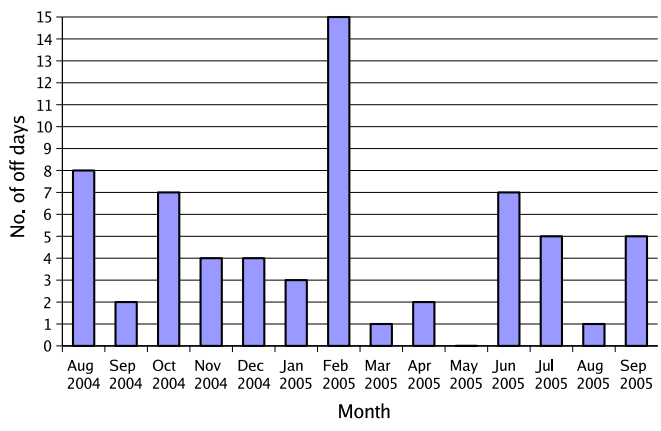

Fig. 4. Count of days without PCO service

The plot showing the number of off days in each month is shown in Figure 4. The link failure was prominent in the month of February 2005 when a technical problem arose with the solar power facility at $V S$ resulting in as many as fifteen off-days. For the other outages, at this time we do not have more detailed information regarding which of the above three causes were responsible for the service unavailability.

\section{B. Business performance}

To understand the financial viability of our model, we collected transaction data from August 2004 to September 2005. For obtaining this information, we used the database at the $L S$.

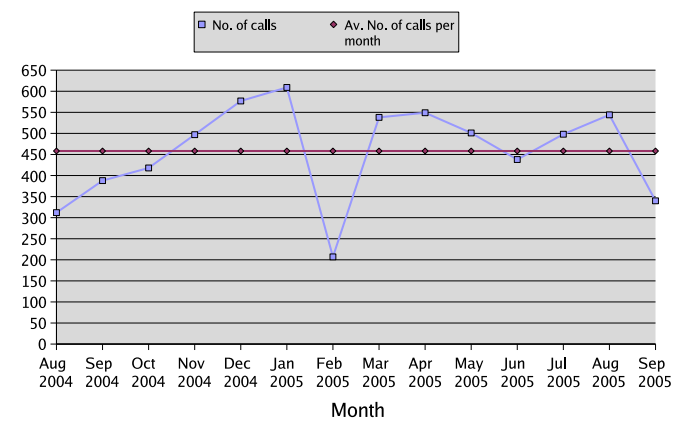

Fig. 5. Number of calls made per month

We first plot the number of calls per month in Figure 5. As can be seen from the plot, there is an increase in the number of calls for the months between August 2004 and January 2005. This can be attributed to the harvesting season, most of the residents of $V S$ being farmers. The month of February 2005 saw the number of calls to decrease as the service was unavailable for half of the month due to technical difficulties.

We next look at the variation of the revenue collected by the PCO operator (from the VoIP customers) for the duration of August 2004 to September 2005. The data for this was also collected from the database at the $L S$. The plot is shown in Figure 6. As can be seen from the plot, the average revenue earned is around $\$ 52$ per month. Note that the plot shows the revenue collected from (or the cost to) the customer at the VS. The way this revenue is shared among the various entities is discussed in detail in Section IV.

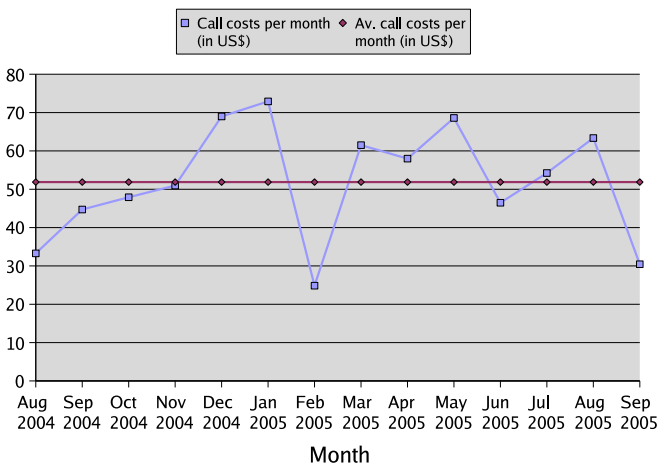

Fig. 6. Call cost (to the customer) per month

While the amount of revenue earned is a good estimator of the popularity/importance of a telephony service, another factor to look out for is the duration for which the services are used by the customers. We plot the time duration of the local as well as long-distance (STD/ISD) calls for the entire data collection period, the source for this is the database maintained at the $L S$. This is shown in Figure 7. We see that while a substantial portion of calls are less than a minute in duration, the majority of the calls is still greater than 1 minute in duration.

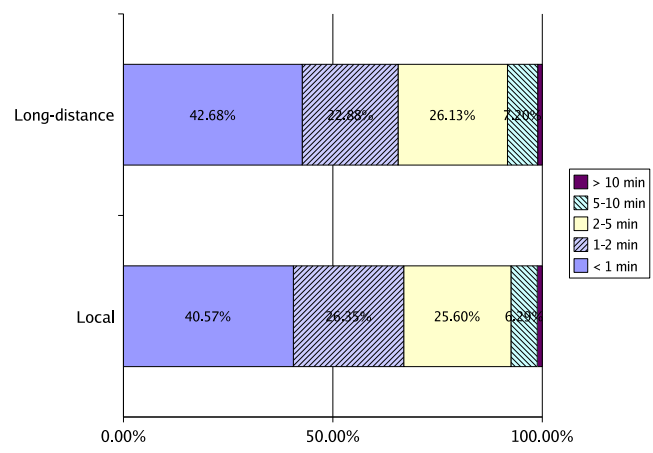

Fig. 7. Duration wise breakdown of calls

We also collected information on the variation of demand for our services throughout a day. This information was maintained by the PCO operator (only) for the month of September 2005 and reported back every next working day to us at the $L S$. This data is depicted in Figure 8.

We see that the usage is distributed through the day, with no specific non-busy periods, except probably $5-7 \mathrm{pm}$. Along with the time-of-day information, we also show information on the sex of the caller. An interesting aspect of this plot 


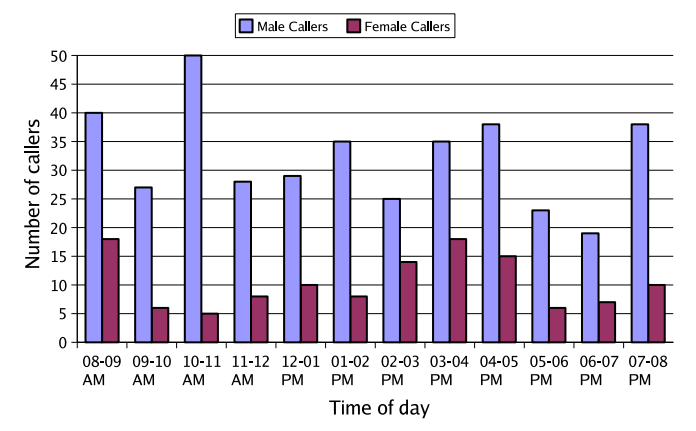

Fig. 8. Time of day when people use the facility (Sep-2005)

is the following. The number of male callers peaks in the period 10-11am, exactly when the number of female callers is at its minimum. This points to the social aspect related to the division of labour in that region. The number of female callers in particular tends to be high during $2-5 \mathrm{pm}$, this is probably because this is the time of day when they are free of their daily chores. However, since this data was collected only for September 2005, this may not be representative of the usage in other months of the year.

We also tracked the destination of the VoIP calls made from the VS. We have found out that most of all the long distance calls were made to two big cities: one being New Delhi, $440 \mathrm{kms}$ away from the $V S$, and the other Mumbai, about $1350 \mathrm{kms}$ from the VS. This can be explained as follows. The village has many orchards of mango. At the time of mango harvest, trading people make calls to these cities, which have big mango markets.

Apart from these observations we have also found out that the reasons affecting our daily business are the following,

1) Weather conditions: People avoid coming to the PCO during rain and extreme cold.

2) Power failure: At any location (PCO at the VS, or the telephone exchange).

The average monthly revenue earned is of the order of $\$ 52$. Although the revenue seems to have peaked under the current setup, we believe that it is possible to improve this with a little more advertising (in neighbouring regions).

\section{Social aspects}

We collected various data related to the social aspects of the VoIP usage. The observations were collected by the PCO operator either for just September 2005, or for the period of September 2005 and October 2005. The observations were tracked for each call made and reported back to us at the $L S$ the next working day.

Figure 9 shows a plot tabulating the various reasons for the VoIP calls made by the customers at the VS. This data was collected for both September as well as October 2005. We see that people usually tend to make casual calls. On inquiring further, we learnt that most of these casual calls tend to be for enquiring about the well being of relatives working in other places: many of the households at the village have family members or relatives working in other locations. A distant second prominent reason for the usage of the VoIP service is for business calls. Again, it is possible that this data may not be representative of the calling pattern during the other months of the year.

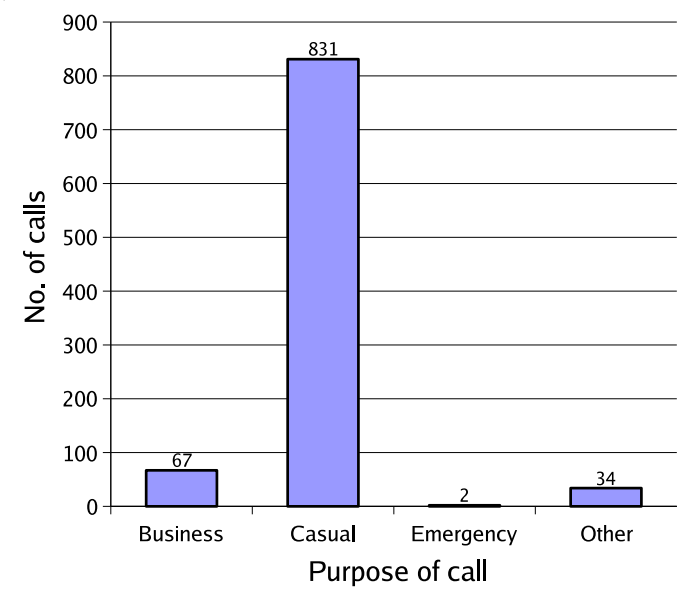

Fig. 9. Purpose of making the calls

Next, Figure 10 classifies the VoIP usage based on the occupation of the caller. This data is only for the month of September 2005. The fact that most of the residents of $V S$ are farmers is reflected in this plot. This underlines the potential benefits of providing targeted ICT services for farmers: like access to market prices of produce, expertise on agriculture related issues like right time to sow crops, best quality of seeds available etc. which will surely enhance the quality of life in the region. The rest of our callers are business-persons, students, service members and home-makers, who can also gain from the presence of tailor-made ICT services.

Figure 11 plots the age profile of the PCO users. This data is for the two months of September and October 2005. We find that majority of our customers are within the age group of 20-30 (about 54\%), while around $17 \%$ are below 20 years of age, whereas $23 \%$ are in the age group of 30-40.

We have also gathered data on the educational profile of the callers in the month of September 2005: the statistics are shown in Figure 12. As can be seen most of the customers are illiterate. If we assume that our clients form a fair representation of the VS populace and that of its vicinity, then this underscores the necessity of providing ICT services like distant (remote) education to the villages. Such remote education services could be easily provided using our WiFi link setup.

\section{Cost Analysis of the Setup}

Having looked at various socio-economic statistics related to the VoIP service operation, we now turn to a financial 


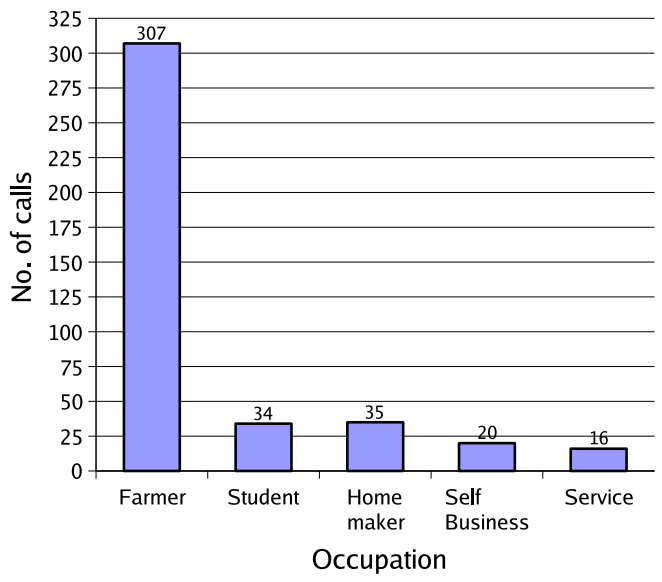

Fig. 10. Occupation wise break-up of the PCO service users

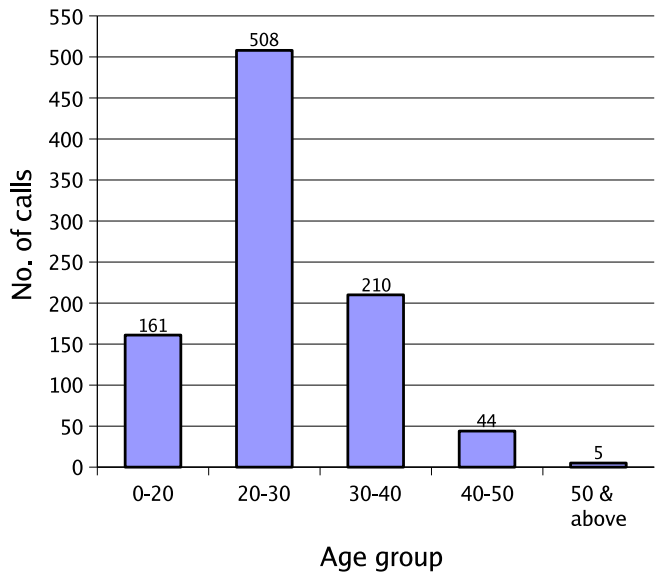

Fig. 11. Age-wise break-up of the PCO service users

viability analysis of the setup. We first provide a break up of the expenses incurred by us (Section IV-A) and the revenues earned from the setup (Section IV-B). We then discuss various possibilities of optimizing the costs incurred in the setup, as well as an alternate revenue sharing model. These lead to a more optimized deployment alternative (Section IV-C).

\section{A. Infrastructure and operating costs}

The cost of the deployment has two main components: the capital expenditure (CapEx), and the operating expenditure (OpEx). The CapEx break-up of the current setup is summarized in the Table I. We have categorized the costs into three parts: equipment related to the WiFi link, VoIP equipment, and the power backup. The antennae are parabolic grid antennae from HyperLinkTech [4]. The RF cables are also from the same vendor. The wireless bridge is Cisco's a350 [5], configured for long distance links, and powered using 802.3af (Power Over Ethernet). The solar power appliance is from

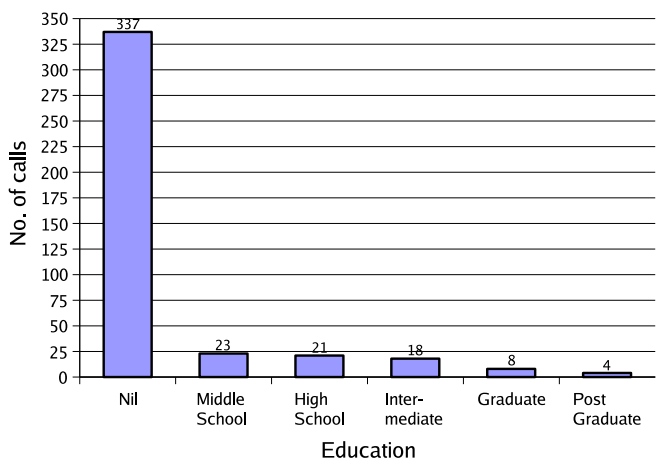

Fig. 12. Educational profi le of the PCO service users

TataBP Solar [6]. The battery used is of 12 Volts, 110 Amperehour rating. All other equipment prices given in the table are the respective common market prices at that time.

\begin{tabular}{|c|c|c|c|c|c|}
\hline \multicolumn{2}{|l|}{ WiFi link } & \multicolumn{2}{|l|}{ VoIP } & \multicolumn{2}{|c|}{ Power backup } \\
\hline Antennae & $\overline{120}$ & $\overline{\text { FXO, FXS }}$ & 160 & $\begin{array}{l}\text { Solar power } \\
\& \text { inverter }\end{array}$ & 1,100 \\
\hline RF cable & 120 & $\begin{array}{l}\text { PCO billing } \\
\text { machine }\end{array}$ & & UPS & 60 \\
\hline $\begin{array}{l}\text { Connectors } \\
\text { \& adapters }\end{array}$ & 50 & Telephone & 10 & $\begin{array}{l}\text { Diesel } \\
\text { Generator }\end{array}$ & 340 \\
\hline $\begin{array}{l}2 \text { wireless } \\
\text { bridges }\end{array}$ & 2,000 & & & & \\
\hline $\begin{array}{l}\text { Antenna } \\
\text { tower }\end{array}$ & 6,600 & & & & \\
\hline Sub-total & 8,890 & Sub-total & 330 & Sub-total & 1500 \\
\hline & & & Total & & $\mathbf{1 0 , 7 2 0}$ \\
\hline
\end{tabular}

TABLE I

CURRENT CAPEX (IN U.S.\$)

The operating head consists of two subparts,

1) Solar panel maintenance: The solar equipment had a problem of interfacing with the inverter, at frequent intervals it stopped charging the inverter for reasons unknown to us, and had to be repaired by mechanics from TataBP Solar [6].

2) RF equipment maintenance: The recurring problems in this head have been the need to reconfigure the wireless bridge parameters. The parameters are often reset to factory default values on rebooting after improper shutdown, caused by power failure.

Throughout the period of deployment the average monthly expenditure under the two heads have been about $\$ 30$ and $\$ 20$ respectively. Another minor recurring expenditure has been the cost of diesel for running the generator (backup power source). The average monthly expenditure for this has been about $\$ 2$. The total OpEx per month is thus about $\$ 52$. A point to be noted with respect to the OpEx is that most of the money spent has been in commute charges (around \$15 per to/fro 
trip), given the distance and relative inaccessibility of the VS from the $L S$.

The above description does not account for the costs incurred at the $L S$ for powering up the equipments and housing the facility. However, the electricity consumption and space occupied by the equipments is minimal and they can be easily accomodated at a small incremental cost. Also, the cost at the central location would be amortized over all the rural locations that it would cover.

\section{B. VoIP service revenue}

Before we analyze the revenue from the service, it is important to note that there are three main entities who are financially involved in the current setup. The first entity is the telephone service provider, which is Bharat Sanchar Nigam Limited (BSNL) in our case. This is the entity which provides the PSTN basic telephony service, in Figure 3. The second entity is the PCO operator who does a well defined work as mentioned in Section I, which entitles him/her to a certain amount of monetary compensation. The third entity is the infrastructure provider who sets up the VoIP deployment. The infrastructure provider is the owner as well as the maintainer of the wireless and telephony equipments. In our case, we are the infrastructure provider, and are stationed at the $L S$.

In this setup, for each call made the generated revenue and its sharing is as follows.

1) The rate of a single pulse (a predefined amount of time used as a unit for billing) of call is $\$ 0.024$. The pulse duration varies with the number being called (shorter duration for more expensive calls). The pulse duration as well as the cost per pulse is fixed by the telephone service provider.

2) The telephone service provider also charges an $8 \%$ service tax (i.e. \$ 0.002) on every pulse. Hence, the net amount due to the telephone service provider for each pulse is $\$ 0.026$.

3) In addition to the above, the PCO operator adds a $\$ 0.04$ amount as service charge on each call, except for local calls and prints the bill. This is the maximum allowed by the telephone service provider. Hence the total amount paid by a customer (at the VS) for each call is $\$ 0.026$ per pulse, plus \$0.04. This is the amount plotted in Figure 6.

The $\$ 0.04$ collected by the PCO operator as service charge along with the call cost is divided as follows. An amount of \$0.02 from the service charge goes towards the infrastructure provider and the PCO operator retains the rest (i.e. $\$ 0.02$ ).

Thus, given that the average number of calls per month is about 450 (see Figure 5), the revenue earned by the infrastructure provider is around $450 \times 0.02=\$ 9$ per month. From the previous section, the operational costs per month is of the order of $\$ 52$. It is thus quite clear that currently the VoIP service is a loss-making venture, and of course, we will not be able to recover the infrastructure investments made. We now discuss the possible ways of optimizing the costs of the deployment.

\section{Cost optimizations}

From the above discussion it is clear that the OpEx is quite high. The CapEx is also very high, despite the use of a relatively low cost wireless technology. There is a need to reduce both these costs. The PCO operator should be ensured of a revenue at least at par with other potential jobs in the locality: this is about $\$ 30$ per month in the locality we have considered. The CapEx is dominated by the antenna tower cost, the wireless bridges, and the solar panel. We now discuss alternatives to these.

The tall antenna tower is required only to achieve line of sight, and to clear the Freznel zone with a sufficient margin $(80 \%)$. Instead of having tall towers at either end, one possibility is to have a central tall tower at the $L S$ and a short antenna mast at the $V S$, still achieving line-of-sight. Such an arrangement can especially be beneficial if a central tower at the $L S$ can provide line-of-sight for several surrounding village sites, thus amortizing the cost of central tower. This is depicted in Figure 13. A non-obvious point to keep in mind is that, although $802.11 \mathrm{~b}$ supports three mutually independent channels of operation, it is possible to have more than one link work simultaneously in the same channel, as shown in [7]. Another way to achieve the sharing would be by using point-to-multipoint links as has been considered in [8]. This essentially implies that the cost of a tower can potentially be amortized over several village sites.

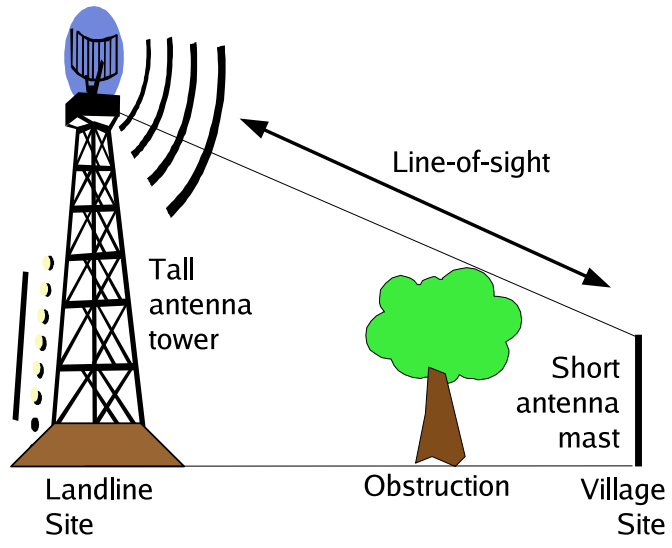

Fig. 13. Achieving line-of-sight with antenna masts

Another advantage of such a setup is that we can potentially use tall buildings, or even pre-existing antenna towers at the $L S$ for the WiFi link (the landline site is typically a big town, or a city, which has tall buildings and cell-phone towers already).

Antenna masts are simply Galvanized Iron (GI) water pipe sections mounted atop one another. Such masts cannot be used for a stable installation beyond a height of about $10-12 \mathrm{~m}$. But the advantage of using antenna masts is that such masts can be very inexpensive. For instance a mast of about $12 \mathrm{~m}$ costs as less as $\$ 80$ [2].

With a central tower at the $L S$ of say $50 \mathrm{~m}$, and assuming 
that the VS uses a $12 \mathrm{~m}$ mast, we can achieve line-of-sight for up to about a distance of $10 \mathrm{~km}$ from the $L S$ to the $V S$. (This can easily be computed from the Freznel zone estimation, assuming a particular height for intermediate obstructions, and using Figure 13). While such a setup may not work in our setting where the $V S$ is $37 \mathrm{~km}$ away from the $L S$, it can work in scenarios where the distances are not as much: say, for less than $10 \mathrm{~km}$.

The next major CapEx in our setup is due to the wireless bridges. We have use the Cisco Aironet 350 [5] series bridges in our installation. These bridges are particularly expensive, perhaps due to the special configuration settings available for long-distance operation. But the required functionality can be replicated with a low cost $\mathrm{PC}$, fitted with an appropriate $\mathrm{WiFi}$ PCI card. This will further lower the CapEx.

There are additional advantages of using a $\mathrm{PC}$ at either end of the setup. It is now possible to replace a stand-alone FXO or FXS box with an appropriate PCI card, which cost much lesser. Another big advantage of using a PC at the $V S$ would be that it can be used for providing other ICT services, further improving the prospect of earning revenue.

Finally, we can use an alternative for the rather expensive solar power panel as follows. We can use SLA (Sealed Lead Acid) battery packs. Apart from being low cost (\$240), it also has the added advantage over solar panels that its operation does not depend on the weather conditions, whereas the operation of a solar panel can deteriorate under cloudy weather. The facility for recharging the SLA batteries is easy to setup, and can be carried out at a nominal expense of as less as $\$ 0.1$ per recharge.

The use of SLA batteries also does away with the operational expenses associated with the solar panel, as well as the cost of buying diesel. The OpEx can now be assumed to be $\$ 52-\$ 30-\$ 2=\$ 20$ per month.

The cost breakup for the optimized deployment scenario is shown in Table II. In this model, the low cost PC is from [9] or [10]. The other equipments costs are common among various equipment vendors as of this writing. Note that we have not included the antenna tower cost at the $L S$. We have assumed that a pre-existing tower or tall building can be used at the $L S$ (as in our current deployment), or that the cost of the tower at the $L S$ gets amortized across multiple village sites.

Apart from using a lower cost setup, we also propose an alternate revenue sharing model next, which involves only the telephone service provider and the PCO operator at the VS.

\section{An alternate revenue sharing model:}

As mentioned previously, the earnings made by the infrastructure provider is very low as that entity is just acting as an intermediary. Even with a low initial deployment cost the amount of revenue earned by the infrastructure builder is unacceptable from a business point of view. An alternative business model which is more financially viable would be one in which the there is no intermediate infrastructure provider and the telephone service provider is the one who makes the

\begin{tabular}{|c|c|c|c|c|c|}
\hline \multicolumn{2}{|l|}{ WiFi link } & \multicolumn{2}{|l|}{ VoIP } & \multicolumn{2}{|c|}{ Power backup } \\
\hline Antennae & 120 & $\begin{array}{l}\text { FXO, FXS } \\
\text { PCI cards }\end{array}$ & 50 & $\begin{array}{l}\text { Battery } \\
\text { pack }\end{array}$ & 240 \\
\hline RF cable & 120 & $\begin{array}{l}\text { PCO billing } \\
\text { machine }\end{array}$ & 160 & $\begin{array}{l}\text { Battery } \\
\text { charger }\end{array}$ & 40 \\
\hline $\begin{array}{l}\text { Connectors } \\
\& \text { adapters }\end{array}$ & 50 & Telephone & 10 & & \\
\hline $\begin{array}{l}2 \text { Low cost } \\
\text { PCs }\end{array}$ & 200 & & & & \\
\hline $\begin{array}{l}2 \mathrm{WiFi} \\
\text { PCI cards }\end{array}$ & 100 & & & & \\
\hline $\begin{array}{l}\text { Antenna } \\
\text { mast }\end{array}$ & 80 & & & & \\
\hline Sub-total & 670 & Sub-total & 220 & Sub-total & 280 \\
\hline & & & Total & & $\overline{\mathbf{1 , 1 7 0}}$ \\
\hline
\end{tabular}

TABLE II

THE OPTIMIZED CAPEX (IN U.S.\$)

initial investment. The VoIP deployment can then viewed upon as an effort undertaken by the telephone service provider to broaden its clientele.

In this scenario, consider a revenue sharing model in which $75 \%$ of the net revenue per month comes to the telephone service provider and the rest $25 \%$ goes to the PCO operator. This is the current revenue sharing scheme adopted by the government owned telephone service provider for rural telephony, of our country.

\section{Financial viability analysis:}

The break even analysis for the conjectured revenue model and the optimized deployment scenario can be worked out easily, as below. The investment on infrastructure is $\$ 1,170$, as shown in Table II, and the operating expenditure is $\$ 20$ per month. The total monthly revenue is $\$ 52$, from Figure 6 . Hence the monthly income for the telephone service provider is $75 \% \times 52=\$ 39$. To recover the CapEx, it would thus take $1,170 /(39-20)=61.57$ months, or a little more than five years. Such a scenario can certainly use improvement, but looks more promising in terms of financially viability than our current deployment setting.

\section{Further economic aspects:}

The economics of rural VoIP telephony has two aspects which we have not considered above explicitly. On the one hand, any VoIP call which originates or terminates in the Indian PSTN requires a license. On the other, the Indian National Telecom Policy 1999 has laid emphasis on Universal Service Obligations (USO) [11], and has provisions for collection of resources for providing rural telephony. These two aspects will also affect the economics of rural VoIP telephony.

\section{COnClusions}

In this paper, we have described our experiences with a VoIP-based telephony service in a rural village setting. We started with a long distance WiFi link setup to a remote village site, and a subsequent VoIP demo run. Given the demand for telephony service at the village, we have sought to maintain 
the VoIP service as a deployment for the past over 15 months. We have presented a wide variety of economic as well as social statistics related to the VoIP service usage.

While we have certainly established the technical feasibility of long distance rural telephony, we have not had the same level of success in the financial aspect. From our experiences with low-cost equipments subsequent to the initial deployment, we have also proposed a new optimized infrastructure deployment model. With support from the relevant basic telephony service provider and an alternate revenue model, it appears that WiFi-link based VoIP deployments can be (barely) financially feasible.

A functional telephony service at a rural location is just a precursor however. Different groups around the world are experimenting currently with various ICT services. For instance, expert advice on agricultural practices is a service being experimented with in the AAQUA (Almost All QUestions Answered) project [12]. The Ashwini project [13] is experimenting with remote education services. Such other services can add value and bring-in revenue to the setup at rural locations. Since the telephony service is well understood and is readily usable by people, it can help in attracting potential customers for the other ICT services which may be offered in the same setup.

\section{ACKNOWLEDGEMENT}

We would like to acknowledge Mr. Monu, the operator at the VS and Mr. Ranjeet Khas of the RuralNet project, IIT Kanpur for maintaining the customer profile data, and especially the former for collecting it as well. We thank all the past and present members of the Digital Gangetic Plains project team for making this long distance VoIP telephony deployment possible. This project was funded by Media Lab Asia.

\section{REFERENCES}

[1] P. Bhagwat, B. Raman, and D. Sanghi, "Turning 802.11 Inside-Out," in HotNets-II, Nov 2003.

[2] B. Raman, "Digital Gangetic Plains: 802.11-based Low-Cost Networking for Rural Areas, 2001-2004: A Report," http://www.iitk.ac.in/ mladgp, Digital Gangatic Plains, Media Labs Asia, Tech. Rep., 2004.

[3] "47cfr15.247," http://frwebgate.access.gpo.gov/cgi-bin/get-cfr.cgi? TITLE $=47 \backslash \&$ PART $=15 \backslash \& \%$ SECTION=247 $\ \&$ YEAR $=2001 \backslash \&$ TYPE $=$ TEXT, Federal Communications Commission.

[4] "2.4 GHz 24 dBi High Performance Reflector Grid Wireless LAN Antenna Model: HG2424G,' http://www.hyperlinktech.com/web/hg2424g. php, Hyperlink Technologies.

[5] "Cisco aironet 350 series bridges," http://www.cisco.com/en/US/ products/hw/wireless/ps458/, Cisco Systems.

[6] "TataBP Solar," http://www.tatabpsolar.com/prod_gallery.html, TataBP solar.

[7] B. Raman and K. Chebrolu, "Design and Evaluation of a new MAC Protocol for Long-Distance 802.11 Mesh Networks," in 11th Annual International Conference on Mobile Computing and Networking paper(Mobicom), Aug/Sep 2005.

[8] V. R. Chimata, "Implementation and Performance Issues of VoIP in Long Distance 802.11b Networks," Masters Thesis, Indian Institue of Technology, Kanpur, Tech. Rep., 2005.

[9] http://www.xenitisgroup.com/index.html, Xenitis Group.

[10] "HCL Ezeebee Pride-A fully functional PC," http://www.hclstore.com/ ezbpride/template.html, HCL Infosystems.

[11] TRAI, "Consultation paper On Universal Service Obligations," http:// www.trai.gov.in/indx.htm, Jul 2000.

[12] “aAqua: almost all questions answered," http://www.aaqua.org.

[13] "Project Ashwini," http://www.byrrajufoundation.org/ashwini_overview. htm, Byrraju Foundation. 